\title{
Stage IB Pleural Malignant Mesothelioma AJCC v8
}

National Cancer Institute

\section{Source}

National Cancer Institute. Stage IB Pleural Malignant Mesothelioma A/CC v8. NCI

Thesaurus. Code C136401.

Stage IB includes: T2 or T3, N0, M0. T2: Tumor involving each of the ipsilateral pleural surfaces (parietal, mediastinal, diaphragmatic, and visceral pleura) with at least one of the following features: involvement of diaphragmatic muscle and/or extension of tumor from visceral pleura into the underlying pulmonary parenchyma. T3: T umor is locally advanced but potentially resectable. The tumor involves all the ipsilateral pleural surfaces (parietal, mediastinal, diaphragmatic, and visceral pleura) with at least one of the following features: involvement of the endothoracic fascia, extension into the mediastinal fat, solitary, completely resectable focus of tumor extending into the soft tissues of the chest wall, and/or nontransmural involvement of the pericardium. N0: No regional lymph node metastases. M0: No distant metastasis. (AJCC 8th ed.) 